\title{
Efeito da adição de probiótico e/ou prebiótico em dietas de leitões desmamados sobre o desempenho, incidência de diarréia e contagem de coliformes totais
}

Fábio Enrique Lemos BUDIÑO'

Maria Cristina THOMAZ ${ }^{1}$

Rodolfo Nascimento

KRONKA $^{1}$

Fernanda Marcussi TUCCI ${ }^{1}$

Alessandro Luís FRAGA ${ }^{1}$

Antônio João

SCANDOLERA ${ }^{1}$

Rizal Alcides Robles

HUAYNATE ${ }^{1}$

Arnaldo NADAI ${ }^{1}$

Rodrigo César CORREIA ${ }^{1}$

Correspondência para:

MARIA CRISTINA THOMAZ

Departamento de Zootecnia da Faculdade

de Ciências Agrárias e Veterinárias

Universidade Estadual Paulista

Via de acesso Prof. Donato Castellane, s/n

14884-900 -Jaboticabal -SP

thomaz@fcav.unesp.br

Recebido para publicação: 29/04/2004 Aprovado para publicação: 13/07/2005
1 - Departamento de Zootecnia da Faculdade de Ciências Agrárias e Veterinárias da Universidade Estadual Paulista, Jaboticabal - SP

\section{Resumo}

Palavras-chave: Antibiótico. Frutoligossacarídeo.

No Experimento 1 foram utilizados 50 leitões desmamados aos 21 dias de idade, alimentados com cinco dietas: T1 - Dieta Basal; T2 Dieta Basal + Antibiótico; T3 - Dieta Basal + Probiótico; T4 - Dieta Simbiótico. Suíno. estudadas foram ganho de peso, consumo de ração e conversão alimentar na Fase 1 ( 21 a 43 dias de idade), Fase 2 (44 a 57 dias de idade), Fase 3 (58 a 70 dias de idade) e Fase Total (21 a 70 dias de idade). Durante o período do experimento de desempenho foi conduzido um levantamento de escores fecais, com o objetivo de se verificar a incidência de diarréia. No Experimento 2, foram utilizados 44 leitões, desmamados aos 21 dias, submetidos às mesmas dietas do Experimento 1. Os leitões foram abatidos em três idades diferentes (dia do desmame, sete e 14 dias pós-desmame). Foi coletado um segmento do intestino delgado para análise de coliformes totais. Melhores resultados de desempenho foram obtidos com a utilização do prebiótico e simbiótico. Não houve diferenças em relação à incidência de diarréia entre os tratamentos estudados. A adição de probiótico e/ ou prebiótico na dieta preveniu o aumento na colonização por bactérias patogênicas dos sete para os 14 dias pós-desmame.

\section{Introdução}

Antibióticos e quimioterápicos são considerados promotores de crescimento tradicionais para aves e suínos. Um grande número de substâncias teve sua eficácia comprovada em melhorar a produtividade dos animais ao longo das últimas cinco décadas e seu uso como microingredientes de rações é generalizado. A melhoria no desempenho dos animais é atribuída à ação desses produtos sobre os microrganismos da flora gastro-intestinal ${ }^{1}$.

Porém, o uso de antimicrobianos nas dietas animais vem sendo questionado em vários países. A razão desta discussão está relacionada com a possibilidade deles serem tóxicos e/ou cancerígenos, comprometendo a saúde humana, quando seus resíduos estiverem presentes em produtos alimentícios de origem animal, causando também problemas de resistência bacteriana aos antibióticos ${ }^{2}$.

Por este motivo, tornou-se crescente a restrição ou proibição ao uso dos antibióticos como promotores de crescimento nas rações animais em vários países do mundo, sendo que na Europa já estão proibidos os usos deste tipo de substância, tais como: virginiamicina, bacitracina de zinco, espiramicina e tilosina ${ }^{3}$.

Baseando-se em novos conceitos de segurança alimentar, produtos alternativos aos promotores de crescimento foram pesquisados e desenvolvidos ${ }^{4}$. O uso destes visa, igualmente, obter o máximo desempenho produtivo animal, com o diferencial de disponibilizar ao mercado um produto 
final sem riscos à saúde do consumidor ${ }^{5}$.

Nesta nova geração de produtos encontram-se os probióticos, os prebióticos e os simbióticos. Os probióticos são suplementos microbianos vivos formados por bactérias ou fungos específicos, capazes de melhorar o equilíbrio microbiano no intestino, uma vez que provocam a redução de agentes patogênicos e estimulam o sistema imune do hospedeiro ${ }^{6}$. Os prebióticos são compostos presentes nos ingredientes da dieta e/ou adicionados a ela, não-digestíveis pelo organismo animal, mas que são seletivamente fermentados, estimulando o crescimento e/ ou a atividade de um grupo restrito de bactérias que agem beneficamente no trato digestivo ${ }^{7}$. O conceito de simbiótico alia o fornecimento de microrganismos probióticos juntamente com substâncias prebióticas específicas que estimulem seu desenvolvimento e atividade, potencializando o efeito de ambos os produtos ${ }^{1}$.

Alguns autores têm observado melhores ganho de peso e conversão alimentar e menor incidência de diarréia em leitões alimentados com dieta contendo probiótico ${ }^{8,9}$. Já os prebióticos têm sido usados com a finalidade de estimular o desenvolvimento das Bifidobacterium e dos Lactobacillus, as quais são conhecidas pela grande capacidade de produzirem ácidos láctico e acético. A maior produção destes ácidos promove a diminuição do $\mathrm{pH}$ no sistema digestório, o que provoca inibição no desenvolvimento das populações de bactérias nocivas, como Escherichia coli, Clostridium sp. e Salmonella sp., as quais apresentam alta sensibilidade a ambientes ácidos $^{10}$.

O presente estudo foi proposto para testar a hipótese de que a suplementação destes microingredientes (pro e prebióticos) podem interferir no desempenho, incidência de diarréia e contagem de coliformes totais de leitões desmamados.

\section{Materiais e Métodos}

\section{Experimento 1}

Foram utilizados 50 leitões, homogê- neos quanto à linhagem (LD x LW), desmamados aos 21 dias de idade com peso médio inicial de 6,18 $\pm 0,68 \mathrm{~kg}$. Os animais foram alojados em baias individuais de 2,55 $\mathrm{m}^{2} /$ leitão $(1,50 \times 1,70 \mathrm{~m})$, separadas por divisória de grades de ferro que foram vedadas com placas de madeirite para evitar o contato entre os leitões. Os bebedouros utilizados foram do tipo vaso-comunicante e os comedouros do tipo semi-automático. Todos os leitões receberam ração e água à vontade e iguais condições de manejo.

Os produtos testados foram: o antibiótico Bacitracina de Zinco (15\%), o probiótico Bio-Plus $2 \mathrm{~B}^{\circledR}$ da CHR - Hansen (Bacillus licheniformis + Bacillus subtilis - 3,2 x $10^{9} \mathrm{UFC} / \mathrm{g}$ ), o prebiótico frutoligossacarídeo (FOS) da Corn Products do Brasil e a associação de probiótico + prebiótico (simbiótico).

O desempenho dos leitões foi avaliado na Fase 1 (21 a 43 dias de idade), Fase 2 (44 a 57 dias de idade), Fase 3 (58 a 70 dias de idade) e Fase Total (21 a 70 dias de idade).

As dietas experimentais foram: T1 Dieta basal; T2 - Dieta basal + Antibiótico (40 ppm); T3 - Dieta basal + Probiótico $(0,13 \%$ de 21 a 43 dias de idade e $0,04 \%$ de 44 a 70 dias de idade); T4 - Dieta basal + Prebiótico $(0,65 \%$ de 21 a 43 dias de idade e $0,20 \%$ de 44 a 70 dias de idade); T5 - Dieta basal + Simbiótico (T3+T4 - nas mesmas inclusões citadas anteriormente). As dietas experimentais, formuladas de modo a atender as exigências nutricionais dos animais, basearam-se nas informações do National Research Concil ${ }^{11}$, e estão apresentadas na tabela 1. A composição das dietas foi calculada a partir das tabelas de Rostagno et al. ${ }^{12}$.

Foram avaliados no desempenho dos animais: o ganho de peso (GP), o consumo de ração (CR) e a conversão alimentar (CA), a partir de valores de peso corporal e consumo de ração, determinados aos 21, 43, 57 e 70 dias de idade.

Foram realizados durante os primeiros 15 dias de experimento observa- 


\begin{tabular}{ccc}
\hline INGREDIENTES & Dieta basal 1 & Dieta basal 2 \\
\hline Farelo de soja & 26,60 & 31,40 \\
Milho & 48,71 & 60,40 \\
Produto lácteo* & 20,00 & 2,00 \\
Açúcar & - & 2,00 \\
Óleo de Soja & - & 0,50 \\
Fosfato bicálcico & 1,20 & 1,20 \\
Calcário calcítico & 0,85 & 0,80 \\
Veículo** & 2,00 & 1,00 \\
Antioxidante BHT & 0,01 & 0,01 \\
DL - Metionina 98\% & 0,04 & 0,02 \\
L - Lisina HCl 78\% & 0,23 & 0,21 \\
L - Treonina 98\% & 0,06 & 0,05 \\
Sal comum & 0,20 & 0,31 \\
Suplemento min. e vit.*** & 0,10 & 0,10 \\
TOTAL & 100,00 & 100,00 \\
Energia metabolizável (kcal/kg) & 3.317 & 3.263 \\
Lactose (\%) & 8,00 & 0,80 \\
Proteína bruta (\%) & 21,1 & 19,5 \\
Lisina (\%) & 1,41 & 1,24 \\
Metionina (\%) & 0,36 & 0,32 \\
Treonina (\%) & 0,90 & 0,79 \\
Triptofano (\%) & 0,28 & 0,23 \\
Cálcio (\%) & 0,81 & 0,72 \\
Fósforo disponível (\%) & 0,47 & 0,32 \\
\hline
\end{tabular}

* Nuklospray K10-40\% lactose;

** Os microingredientes testados foram incluídos em substituição ao veículo (caulim) nas proporções citadas anteriormente;

*** O suplemento mineral e vitamínico não continha qualquer tipo de promotor de crescimento ou antibiótico. Níveis de garantia por kg de ração: Vit. A - 4.000 U.I.; Vit. D -220 U.I.; Vit. E - 22 mg; Vit. K - 0,5 mg; Vit. B - 3,75 mg; Vit. B 120 mg; Pantotenato de Cálcio - 12 mg; Niacina - 20 mg; Colina - 60 mg; lodo - 140 mg; Selênio - 300 mg; Manganês - 10mg; Zinco - 100 mg; Cobre - 10 mg; Ferro - 99 mg.

ções das excretas dos leitões com o objetivo de avaliar a presença de diarréia conforme procedimento descrito por Vassalo et al. ${ }^{9}$. Foi verificada diariamente pela manhã a ocorrência de diarréia, utilizando-se o seguinte critério para os escores fecais: 0 - fezes com consistência normal; 1 - fezes moles; 2 - fezes pastosas e 3 - fezes aquosas, onde 0 e 1 foram considerados não diarréia e 2 e 3 diarréia.

Foi utilizado o delineamento em blocos casualizados para controlar diferenças iniciais de peso, com cinco dietas e 10 repetições, sendo que a unidade experimental foi constituída por um animal. Os valores do escore de diarréia foram transformados (ym $=\operatorname{sqrt}(\mathrm{y}+0,5))$ para posterior análise por se tratar de dados não-paramétricos. Os dados foram analisados através do procedimento "General Linear Model" (GLM) do software estatístico "Statistical Analysis System"13, e as médias comparadas pelo teste de Tukey (5\%).

\section{Experimento 2}

O Experimento 2 foi realizado nas 
mesmas instalações do Experimento 1. Foram utilizados 44 leitões, homogêneos quanto à linhagem (LD x LW), desmamados aos 21 dias de idade com peso médio inicial de $5,40 \pm 0,73 \mathrm{~kg}$. A dieta experimental foi a mesma do Experimento 1, sendo que os leitões receberam apenas a Dieta basal 1, uma vez que foram abatidos com no máximo 14 dias pós-desmame. No dia do desmame foram abatidos 4 leitões (controle) e nos dias 7 e 14 pós-desmame foram abatidos 4 leitões de cada tratamento. Antes de serem abatidos, os animais passaram por um período de jejum alimentar de 16 horas, sem restrição de água.

Imediatamente após o abate, foi coletada amostra da porção média do jejuno $( \pm 3 \mathrm{~cm})$. Nesta porção foi realizada análise quantitativa de coliformes totais segundo a técnica do número mais provável (NMP) de acordo com o método descrito por Siqueira ${ }^{14}$. Foi retirada uma amostra de aproximadamente $25 \mathrm{~g}$, diluída sucessivamente $(1,0,1,0,01)$, destas foram pipetadas alíquotas de $1 \mathrm{~mL}$ para uma série de três tubos de caldo LST, homogeneizados e incubados a $35^{\circ} \mathrm{C} / 48 \mathrm{~h}$. Transcorrido este tempo, foi observada a produção de gás nos tubos de fermentação (tubo de Durham) ou no meio, quando o tubo era agitado suavemente, era anotado o tubo com produção de gás (tubos positivos). Após estes procedimentos reportava-se a tabela do NMP para 3 diluições com 3 tubos em cada diluição ${ }^{14} \mathrm{O}$ resultado era fornecido em NMP de Coliformes ( $\left.\log _{10} \mathrm{UFC} / \mathrm{g}\right)$. Deve-se ressaltar que estas análises foram realizadas utilizando um raspado de mucosa já que os animais permaneceram em jejum antes do abate, portanto o trato intestinal não continha alimento. Desta forma estas contagens microbiológicas referem-se às bactérias que eventualmente estavam aderidas a parede intestinal. Além disso, é um teste presuntivo não sendo possível a identificação das espécies ${ }^{14}$.

Foi utilizado o delineamento em blocos casualizados para controlar diferenças iniciais de peso, em esquema fatorial $5 \times 2+1$ (cinco dietas $\mathrm{x}$ duas épocas de abate + um grupo controle) com quatro repetições, sendo que a unidade experimental foi constituída por um animal. A análise de variância foi realizada através do procedimento GLM do Statistical Analysis System $^{13}$, com as médias dos tratamentos comparadas pelo teste de Tukey (5\%).

\section{Resultados e Discussão}

\section{Desempenho}

As médias de ganho diário de peso (GDP), consumo diário de ração (CDR) e conversão alimentar (CA) obtidas para os diversos tratamentos, nas Fases 1, 2, 3 e Fase Total estão apresentadas na tabela 2 .

Os dados mostraram que a adição dos microingredientes à dieta influenciou $(\mathrm{P}<0,05)$ apenas o CDR na Fase 1 , sendo que no tratamento com probiótico observou-se menor consumo em relação aos animais que receberam a dieta basal. $\mathrm{Na}$ Fase 3, os maiores $(\mathrm{P}<0,05)$ GDP foram observados nos animais que receberam ração contendo prebiótico e os menores naqueles recebendo rações com antibiótico e probiótico, enquanto na fase total os melhores ganhos foram obtidos pelos animais recebendo rações contendo prebiótico e simbiótico e os piores naqueles tratados com antibiótico. Entretanto, Gebbink et al. ${ }^{15}$ observaram que a adição de $5 \%$ de FOS e de $0,05 \%$ do antibiótico virginiamicina na dieta melhoraram em $9 \%$ e $16 \%$ o ganho de peso de leitões desmamados, respectivamente.

Quanto ao probiótico, outros autores ${ }^{16,17}$ verificaram maior eficácia deste tipo de microingrediente como promotor de crescimento em relação ao presente estudo. Outros resultados encontrados na literatura são muito variáveis. Dados de uma revisão relataram melhora de $2,5 \%$ (variação de $-8,5$ a 10,5\%) no ganho de peso e de $6,8 \%$ (variação de $-1,4$ a 21,4\%) na eficiência alimentar em leitões recebendo probióticos ${ }^{18}$. Esta variabilidade nos resultados pode estar associada a diferenças na espécie de 
Tabela 2 - Médias e erro padrão da média do ganho diário de peso (GDP), consumo diário de ração (CDR) e conversão alimentar (CA) dos leitões de acordo com as dietas nas Fases 1 (de 21 a 43 dias), 2 (de 44 a 57 dias), 3 (de 58 a 70 dias) e Total (de 21 a 70 dias de idade).

\begin{tabular}{|c|c|c|c|c|c|}
\hline & Dieta Basal & Antibiótico & Probiótico & Prebiótico & Simbiótico \\
\hline \multicolumn{6}{|l|}{ Fase 1} \\
\hline GDP (g) & $138 \pm 19$ & $104 \pm 8$ & $104 \pm 12$ & $136 \pm 12$ & $143 \pm 16$ \\
\hline CDR (g) & $301 \pm 21^{\mathrm{a}}$ & $251 \pm 11^{\mathrm{ab}}$ & $225 \pm 12^{b}$ & $263 \pm 11^{\mathrm{ab}}$ & $266 \pm 18^{\mathrm{ab}}$ \\
\hline CA & $2,33 \pm 0,20$ & $2,49 \pm 0,12$ & $2,39 \pm 0,26$ & $2,10 \pm 0,24$ & $2,05 \pm 0,32$ \\
\hline \multicolumn{6}{|l|}{ Fase 2} \\
\hline GDP (g) & $305 \pm 55$ & $215 \pm 31$ & $279 \pm 35$ & $277 \pm 25$ & $345 \pm 30$ \\
\hline CDR (g) & $621 \pm 62$ & $442 \pm 39$ & $528 \pm 58$ & $550 \pm 38$ & $609 \pm 46$ \\
\hline CA & $2,31 \pm 0,29$ & $2,24 \pm 0,18$ & $1,97 \pm 0,11$ & $2,06 \pm 0,14$ & $1,81 \pm 0,12$ \\
\hline
\end{tabular}

Fase 3

$\begin{array}{cccccc}\text { GDP }(g) & 586 \pm 67^{\mathrm{ab}} & 472 \pm 45^{\mathrm{b}} & 464 \pm 57^{\mathrm{b}} & 659 \pm 31^{\mathrm{a}} & 618 \pm 31^{\mathrm{ab}} \\ \text { CDR }(\mathrm{g}) & 1148 \pm 124 & 869 \pm 86 & 949 \pm 127 & 1203 \pm 52 & 1125 \pm 53 \\ \text { CA } & 1,96 \pm 0,08 & 1,84 \pm 0,04 & 2,04 \pm 0,08 & 1,83 \pm 0,05 & 1,83 \pm 0,05\end{array}$

Fase Total

\begin{tabular}{|c|c|c|c|c|c|}
\hline GDP (g) & $305 \pm 39^{a b}$ & $233 \pm 21^{b}$ & $250 \pm 30^{\mathrm{ab}}$ & $315 \pm 17^{\mathrm{a}}$ & $327 \pm 17^{\mathrm{a}}$ \\
\hline CDR (g) & $617 \pm 57$ & $470 \pm 33$ & $503 \pm 53$ & $594 \pm 28$ & $592 \pm 30$ \\
\hline CA & $2,09 \pm 0,11$ & $2,04 \pm 0,05$ & $2,08 \pm 0,10$ & $1,90 \pm 0,07$ & $1,81 \pm 0,04$ \\
\hline
\end{tabular}

a,b Médias seguidas de mesma letra na linha não diferem entre si pelo teste de Tukey (5\%).

Tabela 3 - Incidência de diarréia medida em escore fecal nos primeiros 15 dias de experimento

\begin{tabular}{cccccc}
\hline Escore Fecal & Dieta Basal & Antibiótico & Probiótico & Prebiótico & Simbiótico \\
\hline 0 & 39 & 61 & 51 & 56 & 57 \\
1 & 72 & 65 & 50 & 65 & 58 \\
$(0+1)^{*}$ & $(111)$ & $(126)$ & $(101)$ & $(121)$ & $(115)$ \\
2 & 35 & 22 & 39 & 27 & 29 \\
3 & 4 & 2 & 10 & 2 & 6 \\
$(2+3)^{* *}$ & $(39)$ & $(24)$ & $(49)$ & $(29)$ & $(35)$ \\
\hline
\end{tabular}

* Escores 0 e 1 considerados casos normais;

** Escores 2 e 3 considerados diarréia

microrganismo, dosagem, composição da dieta, manejo, interações com drogas e principalmente no nível de desafio sanitário do local.

\section{Escore Fecal}

Os valores do escore fecal observados nas excretas dos leitões durante os primeiros

15 dias de experimento estão apresentados na tabela 3. Na figura 1, estão apresentados os dados de escore fecal transformados.

Não foram observadas diferenças significativas $(\mathrm{P}>0,05)$ entre as médias estudadas. Porém, observando a figura 1 , notou-se um aumento na incidência de diarréia nos primeiros sete dias após a 
desmama em todos os tratamentos, ocorrendo em seguida um equilíbrio até o $15^{\circ}$ dia de avaliação, o que é considerado normal em leitões nesta fase ${ }^{13}$. Vassalo et al. ${ }^{27}$ trabalharam com o mesmo esquema de pontuação ao analisar o escore fecal de leitões dos 10 aos $30 \mathrm{~kg}$ de peso vivo. Nesta ocasião não observaram diferença significativa entre os tratamentos com antibiótico ou probiótico (Lactobacillus acidophilus, Streptococcus faecium e Sacharomyces cerevisae), contudo constataram que os animais que receberam ração contendo probiótico apresentaram menor incidência de diarréia quando comparados com aqueles recebendo a ração controle. Bons resultados no controle da diarréia em leitões desmamados aos 28 dias foram obtidos administrando uma dieta contendo probiótico baseado em Bacillus licheniformis e Bacillus toyoi ${ }^{16}$.

Os dados do presente estudo concordaram com Kirchgessner et al. ${ }^{20}$ os quais verificaram que a utilização de probiótico a base de Bacillus cereus não influenciou a freqüência da diarréia em leitões desmamados. Da mesma forma Santos et al. ${ }^{21}$ não observaram diferenças na incidência de diarréia em leitões na fase de aleitamento e creche quando administraram Lactobacillus sp.

Os resultados da literatura ainda são muito controversos em relação a esta variável e isto se deve às diferenças encontradas nos tipos de probiótico e prebiótico utilizados, dosagem, condições sanitárias (desafio) e ambientais presentes nos experimentos.

\section{Coliformes Totais}

Os resultados da análise de coliformes totais estão apresentados na figura 2 , onde se observou interação significativa $(\mathrm{P}<0,05)$ entre idade e dieta.

Observou-se na figura 2 , aumento significativo do número de colônias $(32 \%)$ dos sete para os 14 dias pós-desmame nos animais que receberam ração com antibiótico. Nos animais recebendo a dieta basal também houve aumento bastante expressivo (93\%), mas não significativo. Já em relação aos outros microingredientes testados a variação foi pequena em comparação às dietas citadas anteriormente. Adami e Cavazzoni ${ }^{22}$ testaram a utilização de Bacillus coagulans e bacitracina de zinco na dieta de leitões constatando decréscimo no número de enterococus e coliformes mais evidente com o uso do probiótico do que com o de antibiótico. Em outros estudos testando o Bacillus cereus como probiótico também se observou uma redução no número de bactérias patogênicas do lúmen intestinal de leitões ${ }^{17,23}$.

$\mathrm{O}$ aumento significativo na contagem de coliformes totais nos animais recebendo ração com antibiótico é explicado pelo fato de que a bacitracina de zinco é ativa frente a bactérias gram-positivas, sem ação sobre gram negativas ${ }^{24}$. Como os gêneros presentes no grupo coliformes são representados por bactérias gram-negativas, tais como: Escherichia, Enterobacter, Citrobacter e Klebsiella ${ }^{14}$, é provável ter havido um desequilíbrio da microbiota, resultando em aumento do número de coliformes na presença da bacitracina de zinco.

Mathew et al..$^{10}$ observaram aumento na concentração de E. coli no îleo de leitões desmamados aos 23 dias de idade, seguido de uma queda na concentração de lactobacilos, fato este que se inverteu aos 41 dias de idade. Nestes mesmos animais foi medido o $\mathrm{pH}$ do íleo, constatando valores elevados $(>7,5)$ ao desmame, seguido de uma queda aos 41 dias $(<7,0)$. Estes dados demonstraram haver uma correlação entre o desenvolvimento de patógenos e o $\mathrm{pH}$ intestinal, o qual atua como uma barreira ao crescimento de microrganismos indesejáveis. Os microingredientes aqui estudados (pro e prebióticos) podem atuar desta forma baixando o $\mathrm{pH}$ do lúmem intestinal $\mathrm{e}$ reduzindo o desenvolvimento de E. coli.

Esta hipótese explica o controle sobre microrganismos patogênicos proporcionado por probióticos e prebióticos por interferir positivamente na produção de ácidos graxos voláteis (AGV), os quais podem também afetar o $\mathrm{pH}$ da porção distal do trato 


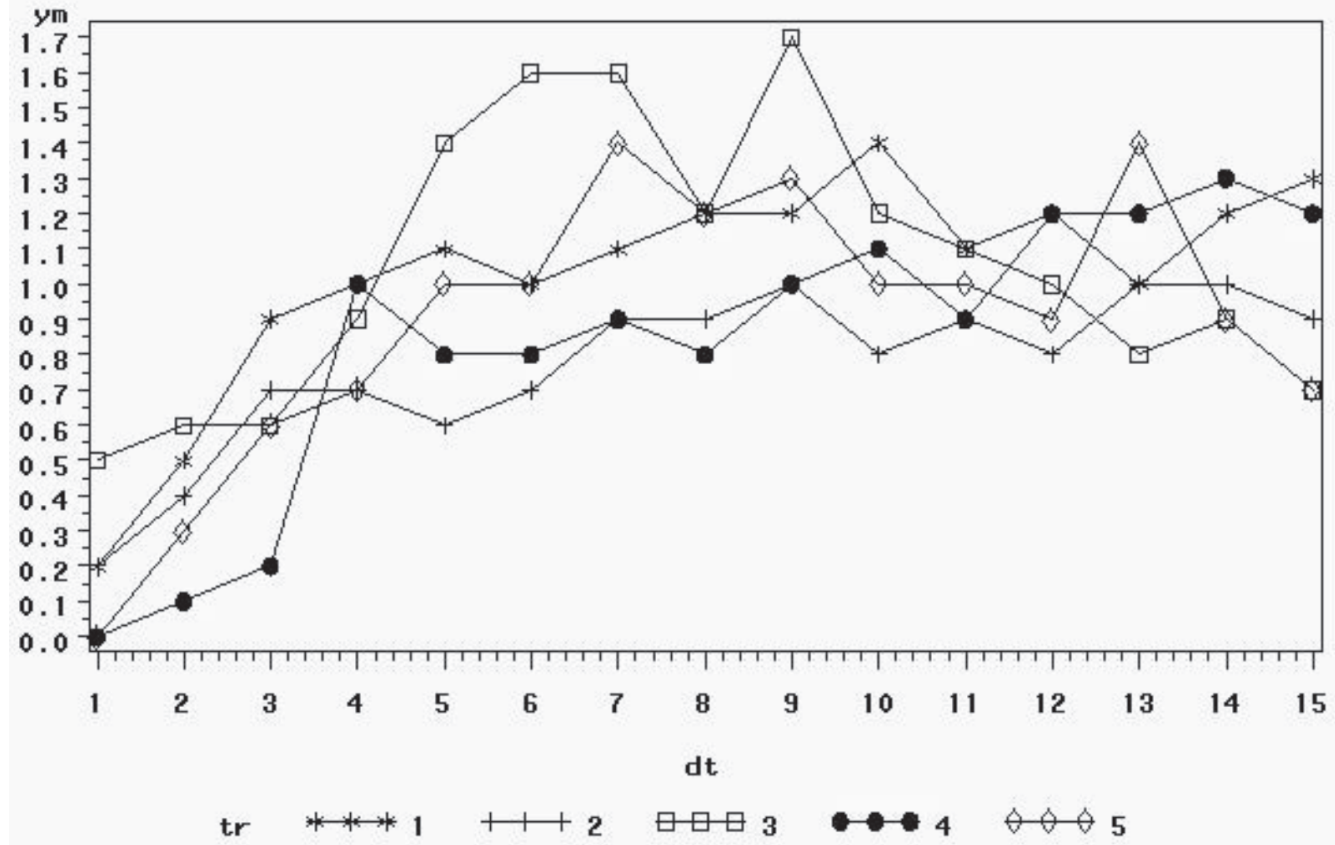

Figura 1 - Incidência de diarréia medida em escore fecal nos primeiros 15 dias de experimento. Não houve diferença significativa entre os tratamentos pelo teste de Tukey (5\%). Sendo que, ym: dados transformados, dt: dias após desmame, tr1: basal, tr2: antibiótico, tr3: probiótico, tr4: prebiótico, tr5: simbiótico

$\log 10$ UFC

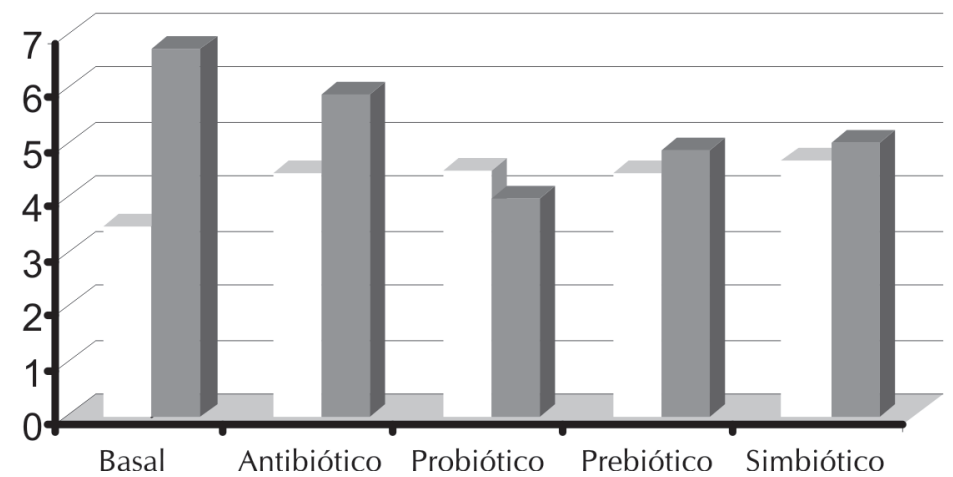

Figura 2-Médias dos tratamentos para a variável Coliformes Totais. Médias do tratamento com "antibiótico" diferem entre si pelo teste de Tukey (5\%)

gastrintestinal ${ }^{25}$. Campbell et al. ${ }^{26}$ verificaram que quando incluíram frutoligossacarídio, xiloligossacarídio ou oligofrutose na dieta de ratos houve redução do $\mathrm{pH}$ do ceco e aumento na concentração de ácidos de fermentação em relação à dieta controle. Efeitos semelhantes foram observados por Gebbink et al..$^{15}$ que relataram uma redução na população de E. coli e aumento da população de bifidobactéria no cólon distal 
de leitões tratados com frutoligossacarídeo a 5\% de inclusão na ração.

Além disso, os probióticos possuem a capacidade de se ligar diretamente à parede intestinal ou às bactérias indesejáveis, impedindo a ação destas. Fato este comprovado por Blomberg, Henriksson e Conway $^{27}$ os quais reportaram que compostos em uma cultura de lactobacilos inibiram o ataque ao intestino de leitões por E. coli K88 patogênica. Alguns autores ${ }^{27,28}$ sugeriram que os compostos produzidos por lactobacilos ou os próprios lactobacilos ligam-se aos receptores da E. coli impedindo a colonização do intestino do hospedeiro baseado em um fenômeno de exclusão competitiva.
Os resultados demonstraram que a adição de probiótico à ração resultou em desempenho dos leitões semelhantes àqueles que receberam as dietas basal e com antibiótico. Melhores resultados de desempenho foram obtidos com a utilização do prebiótico e simbiótico. Não houve diferenças em relação à incidência de diarréia entre os tratamentos estudados. Levando em consideração o aumento da quantidade de coliformes totais nos tratamentos basal e antibiótico entre as idades estudadas, podemos inferir que a adição do probiótico e/ou prebiótico na dieta possivelmente preveniu um aumento na colonização por bactérias nocivas dos 7 para os 14 dias pósdesmame.

\section{Effect of dietary addition of probiotic and/ or prebiotic on performance, diarrhea incidence and total coliforms count of weaned pigs}

\section{Abstract}

In the Experiment 1, 50 pigs weaned at the 21 days were fed with either of five diets: T1 - basal diet; T2 - basal diet + antibiotic; T3 basal diet + probiotic; $\mathrm{T} 4$ - basal diet + prebiotic; $\mathrm{T} 5$ - basal diet + simbiotic. The variables studied were body weight, feed intake and feed conversion in the Phase 1 ( 21 to 43 days), Phase 2 (44 to 57 days), Phase 3 (58 to 70 days) and Total Phase (21 to 70 days). During the performance experiment, a fecal survey score was conducted to verify diarrhea incidence. In the Experiment 2, 44 pigs weaned at 21 days were fed with the same diets of Experiment 1. Pigs were slaughtered at three differents ages (at weaning, at seven and 14 days after weaning). A segment of the small intestine was collected for analisys of total coliformes. The results showed that the best performance was obtained with the utilization of prebiotic and simbiotic. There were not differences in relation to diarrhea incidence among the treatments studied. The addition of probiotic and/or prebiotic in the diet prevented increase of colonization by pathogenic bacterias from seven to 14 days after weaning.

\section{Referências}

1 MENTEN, J. F. M. Aditivos alternativos na nutrição de aves: probióticos e prebióticos. In: REUNIǍ̃ ANUAL DA SOCIEDADE BRASILEIRA DE ZOOTECNIA, 38., 2001, Piracicaba: Anais...Piracicaba, SBZ, 2001. p. 141-157.

2 PENZ Jr., A. M. A produção animal brasileira frente às exigências dos mercados importadores atuais e futuros. In: Reunião Anual da Sociedade Brasileira de Zootecnia, 40., 2003, Santa Maria. Anais... Santa Maria:
SBZ, 2003. CD-ROM.

3 BEST, P. Europa confirma la prohibición de antibióticos. Industria Porcina, v. 19, n. 2, p. 5-6, 1999.

4 MILTENBURG, G. Promotores e Aditivos de Crescimento em Avicultura: Estado da Arte.... In: Conferência APINCO'2000 DE CIÊNCIA E TECNOLOGIA AVÍCOLAS, 2000, Campinas. Anais... Campinas, FACTA: 2000, v. 2, p. 205-215.

5 SILVA, L. P.; NÖRNBERG, J. L. Prebióticos na nutrição de não-ruminantes. Revista Ciência Rural, v. 33, n. 5, p. $983-990,2003$. 
6 WALKER, W. A.; DUFFY, L. C. Diet and bacterial colonization: Role of probiotics and prebiotics. Journal Nutritional Biochemistry, v. 9, p. 668-675, 1998.

7 ROY, M.; GIBSON, G. R. Probiotics and prebiotics - microbial in menu. C-H-O Carbohydrates, v. 9, n. 3, p. 6, 1998.

8 ABE, F.; ISHIBASHI, N.; SHIMAMURA, S. Effect of administration of bifidobacteria and lactic acid bacteria to newborn calves and piglets. Journal Dairy Science, v. 78, p. 2838-2846, 1995.

9 VASSALO, M. et al. Probióticos para leitões dos 10 aos $30 \mathrm{~kg}$ de peso vivo. Revista Brasieira de Zootecnia, v. 26, n. 1, p. 131-138, 1997.

10 MATHEW, A. G. et al. Influence of weaning age on ileal microflora and fermentation acids in young pigs. Nutritional Reserch, v. 6, p. 817-827,1996.

11 NATIONAL RESEARCH COUNCIL. Nutrient requirement of swine. 10th ed. Washington, National Academic Science, 1998. 189 p.

12 ROSTAGNO, H. S. et al. Tabelas brasileiras para aves e suínos - composição de alimentos e exigências nutricionais. Viçosa: UFV, 2000. 141 p.

13 STATISTICAL ANALYSIS SYSTEM. SAS user's guide: Statistics. NC: SAS, 1998, 956 p.

14 SIQUEIRA, R. S. Manual de microbiologia de alimentos. [s. I.] EMBRAPA, CTAA, 1995. 159 p.

15 GEBBINK, G. A. R. et al. Effects of addition of frutooligosaccharide (FOS) and sugar beet pulp to weanling pig diets on performance, microflora and intestinal health. Swine Day Report, p. 6, 1999.

16 KYRIAKIS, S. C. et al. The effect of probiotic LSP 122 on the control of post-weaning diarrhoea syndrome of piglets. Research Veterinay Science, v. 67, n.3, p. 223-228, 1999

17 JADAMUS, A. et al. Influence of the probiotic strain Bacillus cereus var. toyoi on the development of enterobacterial growth and on selected parameters of bacterial metabolism in digesta samples of piglets. Journal Animal Physiology Animal Nutrition, v. 86, n. 1-2, p. 42-54, 2002.

18 CLOSE, W. H. Producing pigs without antibiotic growth promoters. Advances in Pork Production, v. 11, p. 47-56, 2000.

19 JONSSON, E.; CONWAY, P. Probiotics for pigs. In: FULLER, R (Ed.). Probiotics - the scientific basis. London, Chapman \& Hall, 1992. p. 259-316.

20 KIRCHGESSNER, M. et al. The nutritive efficiency of Bacillus cereus as a probiotic in the raising of piglets. 1. Effect on the growth parameters and gastrointestinal enviroment. Archives Tierernahr, v. 44, n. 2, p. 111 121, 1993.

21 SANTOS, M. S. et al. Avaliação da administração de Lactobacillus sp. no desempenho de leitões na fase de aleitamento e de creche. In: Reunião Anual da Sociedade Brasileira de Zootecnia, 35., 1998, Botucatu. Anais... Botucatu: SBZ, 1998. CD-ROM.

22 ADAMI, A.; CAVAZZONI, V. Occurrence of selected bacterial groups in the faeces of piglets fed with Bacillus coagulans as probiotic. Journal Basic Microbiology, v. 39, n. 1, p. 3-9, 1999.

23 GEDEK, B. et al. The nutritive effect of Bacillus cereus as a probiotic in the raising of piglets. 2. Effect and microbial count, composition and resistance determination of gastrointestinal and fecal microflora. Archives Tierernahr, v. 44, n. 3, p. 215-226, 1993.

24 BARCELLOS, D. E. S. N. de; SOBESTIANSKY, J. Uso de antimicrobianos em suinocultura. Goiânia: [s. n.], 1998, 103 p.

25 ÁVILA, F. A. et al. Use of vaccine and probiotic in the control of swine diarrhea caused by enterotoxigenic Escherichia coli. Arquivo Brasileiro de Medicina Veterinária e Zootecnia, v. 50, n. 5, p. 505-511, 1998.

26 CAMPBELL, J. M.; FAHEY, G. C.; WOLF, B. W. Selected indigestible oligossacharides affect large bowel mass, cecal and fecal short-chain fatty acids, $\mathrm{pH}$ and microflora in rats. Journal Nutrition, v. 127, p.130136, 1997.

27 BLOMBERG, L.; HENRIKSSON, A.; CONWAY, P.L. Inhibition of adhesion of Escherichia coli K88 to piglet ileal mucus by Lactobacillus sp. Applied Environment Microbiology, v. 59, p. 34-39, 1993.

$28 \mathrm{CHOCT}, \mathrm{M}$. Alternatives to in-feed antibiotics in monogastric animal industry. ASA Technical Bulletin, v. 30, p. 6, 2001. 